\title{
Kemungkinan Terjadinya Retak pada Balok Pratekan Full Prestressing
}

\author{
M. Sigit Darmawan \\ Dosen Jurusan Diploma Teknik Sipil, Institut Teknologi Sepuluh Nopember \\ Email: msdarmawan@ce.its.ac.id
}

\begin{abstract}
ABSTRAK
Pada tulisan ini akan disajikan perhitungan tegangan yang terjadi pada penampang balok sistem full prestressing, dengan memperhitungkan variabilitas sifat-sifat beton, baja dan beban yang bekerja. Variabitas sifat-sifat beton, baja dan beban yang bekerja akan dimasukkan dalam analisa perhitungan dengan memakai teori kemungkinan (probability analysis). Mengingat sangat terbatasnya data parameter statistik untuk kondisi Indonesia, maka parameter statistik yang diperlukan untuk perhitungan tegangan akan diambil dari berbagai penelitian sebelumnya yang pada umumnya dilakukan di luar Indonesia. Hasil studi menunjukkan bahwa meskipun balok pratekan sudah didisain dengan memakai sistem full prestressing (tidak ada tegangan tarik pada penampang), dari perhitungan dengan memakai probabilty analysis didapat kemungkinan sebesar $\pm 50 \%$ akan terjadi tarik pada serat terbawah. Tegangan tarik yang terjadi tersebut selanjutnya ada kemungkinan sebesar $\pm 20 \%$ akan melebihi tegangan tarik yang diijinkan. Hal ini menunjukkan bahwa pada sistem full prestressing masih terdapat kemungkinan terjadinya retak.
\end{abstract}

Kata kunci: Full prestresing, Probability Analysis, Tegangan Tarik, Retak

\section{PENDAHULUAN}

Pada disain balok pratekan dikenal adanya 2 sistem pemberian pratekanan (Warner dkk, 1998), yaitu

- Full prestressing

- Partial prestressing

Pada sistem full prestressing, seluruh penampang balok beton direncanakan dalam kondisi mengalami tegangan tekan (tidak ada tarik sama sekali), dan sebaliknya pada sistem partial prestressing penampang beton diijinkan mengalami tegangan tarik. Tegangan tarik yang terjadi pada sistem partial prestressing dibatasi nilainya, agar tidak melebihi nilai yang dijinkan. Mengingat kuat tarik beton hanya sebesar $10 \%$ dari kuat tekan beton dan sifatnya yang sangat erratic (variatif sekali), maka pada umumnya dipakai tulangan baja pasif untuk memikul tegangan tarik yang terjadi pada penampang balok pratekan partial prestressing, serta untuk keperluan mengendalikan besarnya retak yang terjadi.

Pada tulisan ini akan ditunjukkan bahwa meskipun balok sudah direncanakan memakai sistem full prestressing (seluruh penampang beton menerima tegangan tekan), kemungkinan terjadinya tarik pada sebagian penampang beton masih mungkin akan terjadi. Penyebab utama terjadinya tarik disebabkan antara lain adalah adanya ketidaktentuan pada sifat-sifat material beton, baja dan besarnya beban yang bekerja. Adanya ketidaktentuan tersebut menyebabkan tegangan yang terjadi pada sebuah penampang merupakan sebuah nilai yang bervariasi dan bukannya sebuah nilai yang dapat ditentukan dengan secara pasti (deterministic). Untuk itu akan dilakukan perhitungan tegangan pada penampang balok full prestressing, dengan memasukkan variabitas sifat-sifat beton, baja dan beban yang bekerja. Variabilitas sifat-sifat beton, baja dan beban tersebut akan diperhitungkan dengan memakai analisa teori kemungkinan (probability analysis).

\section{TINJ AUAN PUSTAKA}

Balok pratekan sistem full prestressing dipakai untuk kondisi dimana tidak boleh terjadi retak sama sekali. Sistem ini dipakai antara lain dipakai pada (Warner dkk, 1998):

Halaman 20 J urnal APLIKASI: Media Informasi \& Komunikasi Aplikasi Teknik Sipil Terkini 
- $\quad$ Struktur pelindung (misalnya atap) yang tidak boleh terjadi kebocoran

- Tangki air atau bahan kimia berbahaya lainnya

- Containment structure seperti dipakai pada instalasi reaktor nuklir

- Bangunan di lingkungan yang sangat agresif atau korosif

Mengingat pentingnya peranan bangunanbangunan yang direncanakan memakai sistem full prestressing diatas, maka perlu adanya kepastian bahwa tidak akan terjadi retak sama sekali untuk menghindari terjadinya hal-hal yang tidak diinginkan, misalnya bocornya bahan kimia yang berbahaya.

Penyebab utama terjadinya retak pada balok pratekan full prestressing adalah adanya ketidaktentuan sifat-sifat beton, baja dan beban yang bekerja. Dengan adanya ketidaktentuan ini, maka nilai tegangan yang terjadi pada penampang beton bukan merupakan nilai yang dapat ditentukan dengan tepat (determinisitic), tetapi nilai ini merupakan sebuah variable acak (random variable), yang mempunyai nilai rata-rata (mean) dan sebaran tertentu (coefficient of variation).

Sifat-sifat beton yang perlu diperhitungkan dalam menentukan besarnya tegangan yang terjadi pada sebuah penampang balok pratekan adalah

- Dimensi penampang

- Mutu beton $\left(\mathrm{f}_{\mathrm{c}}{ }^{\prime}\right)$

- Modulus elastis beton

- Susut

- Rangkak

Sedangkan sifat-sifat baja perlu yang diperhitungkan dalam menentukan besarnya tegangan yang terjadi pada sebuah penampang balok pratekan adalah

- Modulus elastis baja

- Mutu baja $\left(f_{\mathrm{pu}}\right)$

- Relaksasi baja

Disamping sifat-sifat beton dan baja diatas, beban yang terjadi juga mempunyai nilai ketidaktentuan yang cukup besar. Sehingga dipakai untuk menentukan besarnya tegangan yang terjadi. variabilitas beban yang terjadi perlu diperhitungkan, baik yang disebabkan beban mati maupun beban hidup. Pada studi tahap ini hanya pengaruh beban mati saja yang diperhitungkan. Pengaruh lingkungan yang berupa suhu dan kelembaban juga diperhitungkan karena mempengaruhi besarnya susut dan rangkak yang terjadi, yang pada akhirnya berpengaruh pada besarnya tegangan yang terjadi pada penampang balok.

Adapun perumusan untuk menentukan besarnya tegangan pada penampang beton akibat pengaruh gaya pratekan dan beban yang bekerja adalah sbb:

$f_{c t}=-\frac{F}{A}+\frac{F * e * h / 2}{I}-\frac{M * h / 2}{I}$ .....(1)

$\mathrm{f}_{\mathrm{cb}}=-\frac{\mathrm{F}}{\mathrm{A}}-\frac{\mathrm{F} * \mathrm{e} * \mathrm{~h} / 2}{\mathrm{I}}+\frac{\mathrm{M} * \mathrm{~h} / 2}{\mathrm{I}} \ldots . .(2)$

dimana

$\mathrm{f}_{\mathrm{ct}}=$ tegangan beton pada serat teratas

$f_{c b}=$ tegangan beton pada serat terbawah

$\mathrm{F}=$ besarnya gaya pratekan efektif

e = eksentrisitas baja pratekan

$\mathrm{h}=$ tinggi penampang balok

$A=$ luas penampang

$\mathrm{I}=$ momen inersia penampang

$M=$ momen lentur akibat beban yang bekerja

\section{PARAMETER STATISTIK YANG DIPAKAI}

Mengingat belum terdokumentasinya dengan baik data penelitian di Indonesia, maka parameter statistik yang akan dipakai untuk perhitungan tegangan yang terjadi dengan memakai analisa teori kemungkinan adalah memakai parameter statistik yang berasal dari penelitian di luar Indonesia (lihat Tabel 1). Tabel 1 menunjukkan bahwa parameter statistik dari sifat-sifat beton mempunyai koefisien variasi yang lebih besar dibandingkan parameter statistik sifat-sifat baja. Hal ini berarti parameter beton akan mempunyai pengaruh yang lebih besar dibandingkan parameter baja pada saat 
Tabel 1: Parameter Statistik yang Dipakai

\begin{tabular}{|c|c|c|c|c|}
\hline Parameter & Rata-rata & COV & Distribution & Referensi \\
\hline $\begin{array}{c}\mathrm{D} \\
\text { (beban mati) }\end{array}$ & $1.05 D_{\text {nom }}$ & 0.1 & Normal & Nowak et al. (2001) \\
\hline $\begin{array}{c}\varepsilon_{\mathrm{cs.b}} \\
\text { (regangan susut dasar } \\
\text { rencana) }\end{array}$ & $750 \times 10^{-6}$ & $144 \times \times 10^{-6}$ & $\begin{array}{l}\text { Uniform } \\
(500-1000) \times 10^{-6}\end{array}$ & AS 3600 \\
\hline $\begin{array}{c}\phi_{\text {cc.b }} \\
\text { (faktor rangkak dasar) }\end{array}$ & 2.5 & 0.43 & $\begin{array}{l}\text { Uniform } \\
(3.25-1.75)\end{array}$ & AS 3600 \\
\hline $\begin{array}{c}\mathrm{R}_{\mathrm{b}}(\%) \\
\text { (faktor relaksasi dasar) }\end{array}$ & 1.5 & 0.29 & $\begin{array}{l}\text { Uniform } \\
(1-2)\end{array}$ & AS 3600 \\
\hline $\begin{array}{c}\mathrm{f}_{\mathrm{c}}(\mathrm{MPa}) \\
\text { (kuat tekan beton) }\end{array}$ & $\mathrm{F}^{\prime \mathrm{a}}{ }_{\mathrm{c}}+7.5$ & $s^{b}=6$ & Lognormal & Attard and Stewart (1998) \\
\hline $\begin{array}{c}\mathrm{E}_{\mathrm{c}}(\mathrm{t})(\mathrm{MPa}) \\
\text { (modulus elastis beton) }\end{array}$ & $4600 \sqrt{f_{c}^{\prime}(t)}$ & - & - & Mirza et al. (1979) \\
\hline $\operatorname{ME}^{C}\left(E_{c}(t)\right)$ & 1.0 & 0.12 & Normal & - \\
\hline $\begin{array}{c}\mathrm{E}_{\mathrm{p}}(\mathrm{MPa}) \\
\text { (modulus elastis baja) }\end{array}$ & 195000 & 0.02 & Normal & Mirza et al. (1980) \\
\hline $\begin{array}{c}\mathrm{f}_{\mathrm{pu}}(\mathrm{MPa}) \\
\text { (tegangan max baja) }\end{array}$ & $1.04 f_{p k}$ & 0.025 & Normal & Mirza et al. (1980b) \\
\hline $\begin{array}{c}\mathrm{H}(\mathrm{mm}) \\
\text { (Tinggi balok) }\end{array}$ & $\mathrm{H}_{\mathrm{nom}}+0.8$ & $s=3.6$ & Normal & $\begin{array}{c}\text { Mirza and McGregor } \\
\text { (1979b) }\end{array}$ \\
\hline $\begin{array}{c}\text { B (mm) } \\
\text { (lebar balok) }\end{array}$ & $\mathrm{B}_{\mathrm{nom}}+2.5$ & $S=3.7$ & Normal & $\begin{array}{l}\text { Mirza and McGregor } \\
(1979 b)\end{array}$ \\
\hline ME(Susut) & 1.0 & 0.34 & Normal & Bazant and Baweja (1995) \\
\hline ME(Rangkak) & 1.0 & 0.23 & Normal & Bazant and Baweja (1995) \\
\hline $\begin{array}{c}\mathrm{RH}(\%) \\
\text { (kelembaban relatif) }\end{array}$ & 80 & 0.1 & Normal & Stewart (1996) \\
\hline $\begin{array}{c}\mathrm{t}_{\mathrm{e}}\left({ }^{\circ} \mathrm{C}\right) \\
\text { (temperatur rata-rata } \\
\text { tahunan) }\end{array}$ & 27.5 & 0.1 & Normal & - \\
\hline
\end{tabular}

Analisa teori kemungkinan dilakukan dengan melakukan simulasi Monte Carlo (Melchers, 1999). Simulasi Monte Carlo dilakukan dengan memasukkan sebuah nilai dari setiap variabel yang terlibat kedalam perumusan tegangan yang terjadi pada penampang dengan secara acak (random) sesuai dengan tipe distribusinya. Langkah ini dilakukan 
berulangkali untuk mendapatkan nilai tegangan yang terjadi yang dapat diterima secara statistik, misalnya dengan melakukan 1000000 simulasi. Dengan tersedianya perangkat keras komputer yang relatif cepat, simulasi sebanyak ini telah dapat dilakukan dalam waktu yang singkat.

\section{APLIKASI PERHITUNGAN}

Sebagai contoh perhitungan, maka dilakukan perhitungan tegangan yang terjadi untuk balok pratekan dengan dimensi seperti Gambar 1 (Warner dkk, 1998).

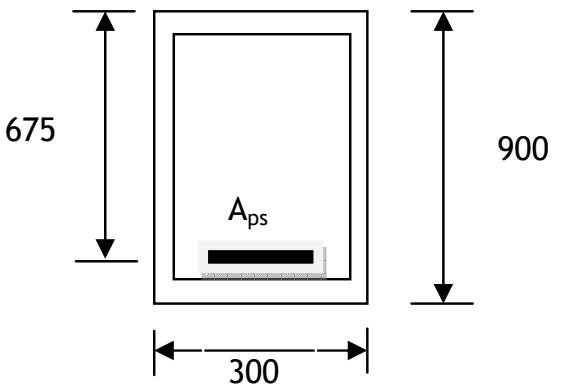

Gambar 1: Balok Pratekan $30 \mathrm{~cm}$ x $90 \mathrm{~cm}$.

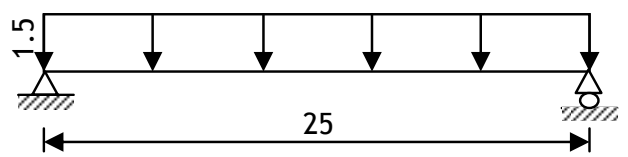

Gambar 2: Balok dengan bentang 25 meter.

Sedangkan data disain yang dipakai adalah sebagai berikut:

$\mathrm{f}^{\prime}{ }_{\mathrm{c}}$ (kuat tekan) $=40 \mathrm{MPa}$

$A_{p s}$ (luas penampang baja $)=3643 \mathrm{~mm}^{2}$

$f^{\prime}{ }_{c i}($ kuat tekan saat transfer $)=30 \mathrm{MPa}$

$\mathrm{E}_{\mathrm{p}}$ (modulus elastis baja) $=195000 \mathrm{MPa}$

$\mathrm{f}_{\mathrm{si}}$ (tegangan awal baja pratekan) $=1100 \mathrm{Mpa}$

$D_{\text {nom }}($ beban mati $)=1.5 \mathrm{t} / \mathrm{m}$

$\mathrm{L}$ (bentang) $=25 \mathrm{~m}$

Dengan memakai persamaan 1 dan 2, maka besarnya tegangan pada penampang beton teratas $\left(f_{c t}\right)$ adalah sebesar $-22.85 \mathrm{MPa}$ (tekan) dan pada penampang beton terbawah $\left(f_{c b}\right)$ adalah sebesar -1.50 MPa (tekan). Tidak terjadi tarik pada penampang beton, sesuai dengan disain memakai sistem full prestressing.

\section{HASIL YANG DIPEROLEH}

Selanjutnya dilakukan perhitungan tegangan pada penampang beton dengan memakai Monte Carlo simulation. Hasil perhitungan disajikan secara berurutan pada Gambar 3, 4, 5 dan 6. Besarnya tegangan yang terjadi dinyatakan dalam MPa, dimana tegangan negatif menunjukkan penampang dalam keadaan menerima tegangan tekan dan positif bila menerima tegangan tarik.

Gambar 3 menunjukkan tegangan yang terjadi pada penampang beton serat teratas, sementara Gambar 4 menunjukkan tegangan yang terjadi pada penampang beton serat terbawah. Gambar 3 mengindikasikan bahwa tegangan tekan yang terjadi pada serat teratas penampang beton bervariasi antara -15 $\mathrm{MPa}$ s/d $-35 \mathrm{MPa}$, dengan rata-rata sebesar -24.09 MPa dan standar deviasi sebesar $3.05 \mathrm{MPa}$. Sama sekali tidak terjadi tarik di daerah ini.

Gambar 4 mengindikasikan bahwa tegangan yang terjadi pada serat terbawah penampang beton bervariasi antara -15 $\mathrm{MPa}$ s/d $16 \mathrm{MPa}$, dengan rata-rata sebesar 0.032 $\mathrm{MPa}$ dan standar deviasi sebesar 3.45 MPa. Berbeda dengan penampang beton bagian teratas yang tidak terjadi tarik sama sekali, pada serat terbawah terdapat kemungkinan terjadi tegangan tarik. Tegangan tarik yang terjadi bahkan telah melebihi tegangan tarik yang diijinkan, yaitu sebesar $0.5\left(f_{\mathrm{c}}{ }^{\prime}\right)^{0.5}$ atau sebesar 3.16 MPa (ACI318, 2002). Gambar 3 dan 4 juga menunjukkan bahwa tegangan pada serat terbawah mempunyai standar deviasi yang sedikit lebih besar dibandingkan tegangan pada serat teratas. 


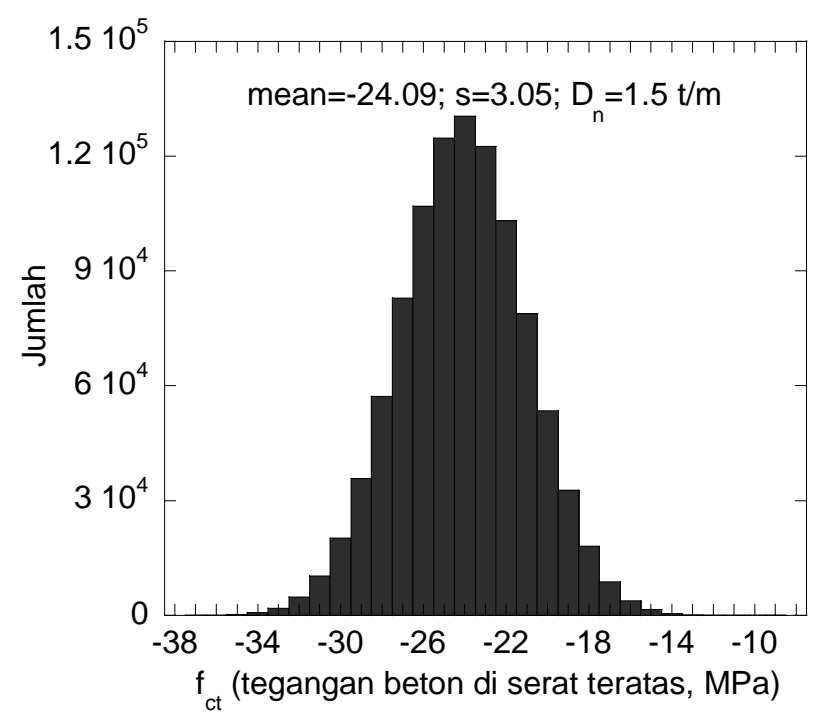

Gambar 3: Tegangan beton di serat teratas.

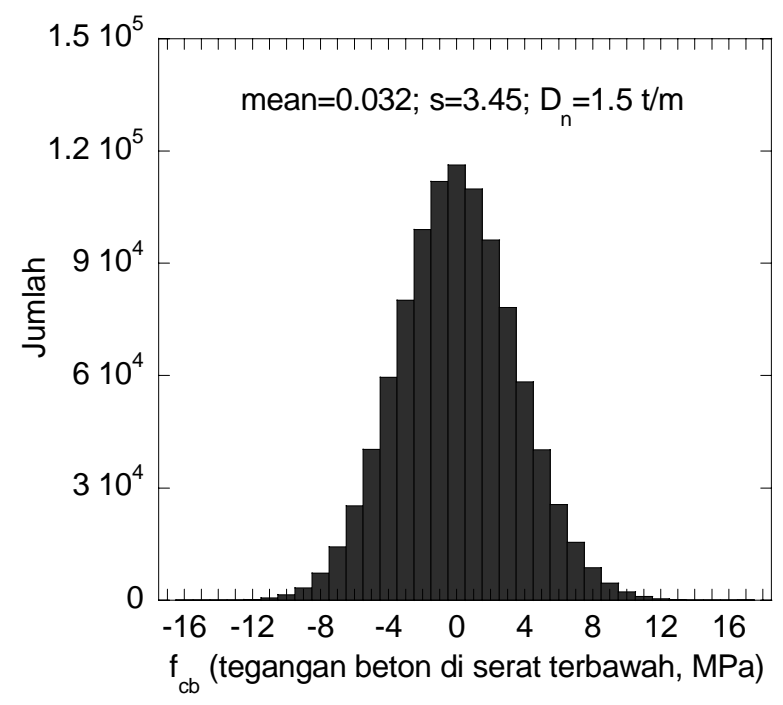

Gambar 4: Tegangan beton di serat terbawah. 


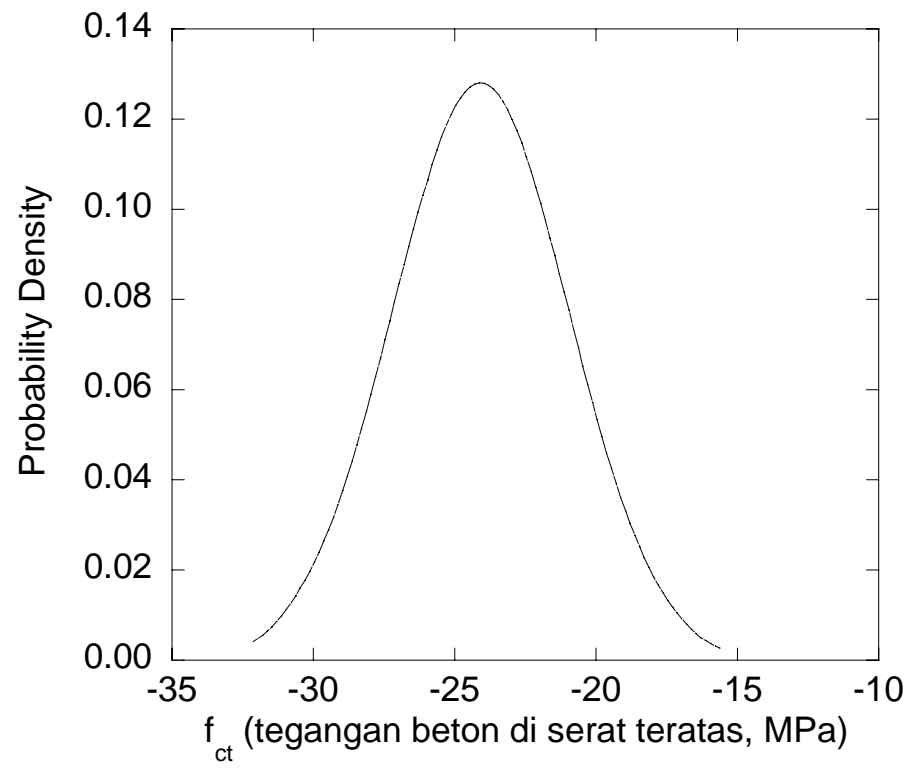

Gambar 5: Distribusi tegangan beton di serat teratas.

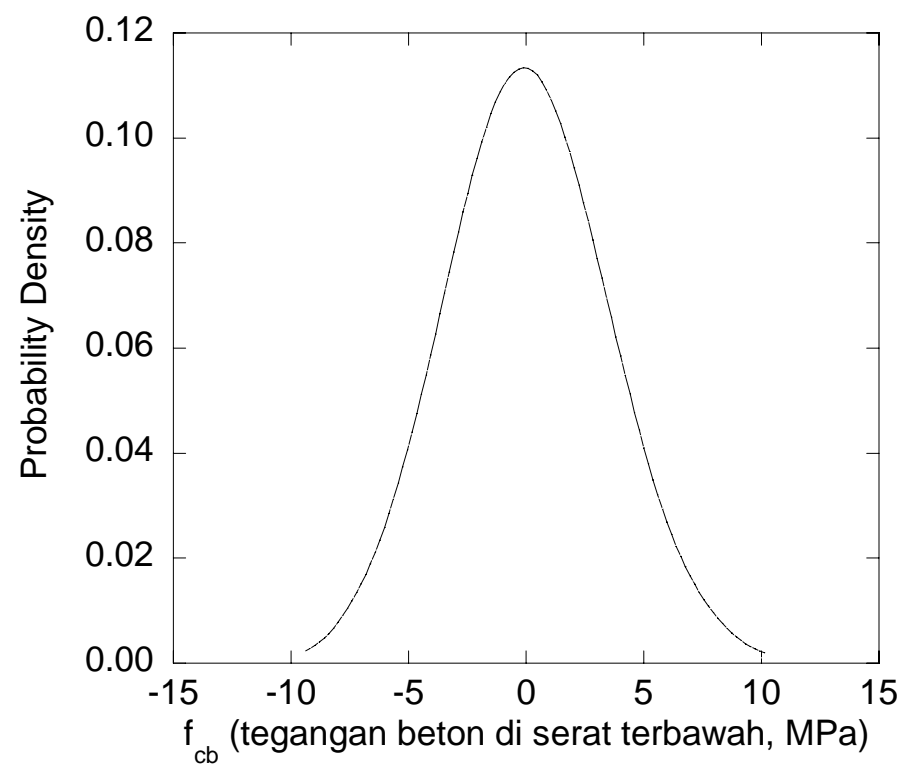

Gambar 6: Distribusi tegangan beton di serat terbawah.

Gambar 5 dan 6 secara berurutan menyajikan distribusi tegangan yang terjadi pada penampang beton bagian teratas dan terbawah. Gambar 5 menunjukkan bahwa tidak ada kemungkinan sama sekali terjadi tarik pada penampang beton serat teratas. Sebaliknya Gambar 6 menunjukkan bahwa kemungkinan terjadinya tarik pada penampang beton serat terbawah cukup besar, yaitu sebesar $\pm 50 \%$. Sedangkan 
tegangan tarik yang melebihi tegangan ijin tarik pada daerah ini mempunyai kemungkinan terjadi sebesar $\pm 20 \%$. Hal ini dapat terjadi karena adanya variabilitas sifat-sifat beton, baja dan beban yang bekerja, yang mengakibatkan terjadi variasi tegangan yang terjadi, meskipun penampang telah didisain dengan memakai sistem full prestressing (tidak ada tarik pada penampang beton). Terjadinya tegangan tarik ini selanjutnya dapat menimbulkan retak yang tentunya sangat tidak diharapkan terjadi pada sistem full prestressing.

\section{KESIMPULAN \& SARAN}

Hasil perhitungan tegangan dengan memakai teori kemungkinan menunjukkan bahwa pada penampang balok pratekan sistem full prestressing terdapat kemungkinan sebesar $\pm 50 \%$ terjadi tegangan tarik pada serat terbawah, meskipun sudah didisain dengan konsep full prestressing (tidak ada tarik). Hal ini terjadi karena adanya variabilitas sifat-sifat baja dan beton serta beban yang bekerja, yang mengakibatkan nilai tegangan yang terjadi juga bervariasi.

Dari hasil perhitungan juga didapatkan bahwa tegangan tarik yang terjadi ada kemungkinan sebesar $\pm 20 \%$ akan melebihi tegangan tarik ijinnya. Tentu saja hal ini juga menunjukkan bahwa masih ada kemungkinan yang cukup besar akan terjadi retak pada balok sistem full prestressing.

Dari hasil diatas maka disarankan bahwa meskipun balok pratekan telah didisain dengan sistem full prestressing, maka sebaiknya tetap diberi tulangan baja pasif pada daerah serat bawah untuk menghindari terjadinya retak.

\section{DAFTAR ACUAN}

ACI 318 (2002), Building Code Requirement for Sructural Concrete $(\mathrm{ACl} 318-02)$ and Commentary (ACl 318R-02), American Concrete Institute, Farmington Hills, Michigan.
AS 3600 (2001), Concrete Structures, Standards Association of Australia, Homebush, New South Wales, Australia.

Attard, M. M. and Stewart, M. G. (1998), A Two Parameter Stress Block for Model for High Strength Concrete, $\mathrm{ACl}$ Structural Journal, ACl, Vol. 95, No. 3, pp. 305-317.

Bazant, Z. P. and Baweja, S. (1995), Creep and Shrinkage Prediction Model for Analysis and Design of Concrete Structures-model B3, Materials \& Structures, Vol. 28, pp. 357-365.

Melchers, R. E. (1999), Structural Reliability Analysis and Prediction, John Wiley \& Sons, New York.

Mirza, S. A., Hatzinikolas, M. and MacGregor, J. G. (1979), Statistical Description of Strength of Concrete, Journal of the Structural Division, ASCE, Vol. 105, No. ST6, pp. 1021-1037.

Mirza, S. A., Kikuchi, D. K. and MacGregor, J. G. (1980), Flexural Strength Reduction Factor for Bonded Prestressed Concrete Beams, $\mathrm{ACl}$ Journal, Vol. 77, No. 4, pp. 237-246.

Mirza, S. A. and MacGregor, J. G. (1979b), Variations in Dimensions of Reinforced Concrete Members, Journal of the Structural Division, ASCE, Vol. 105, No. ST4, pp. 751-766.

Nowak, A. S., Park, C. and Casas, J. R. (2001), Reliability Analysis of Prestressed Concrete Bridge Girders: Comparison of Eurocode, Spanish Norma IAP and AASHTO LRFD, Structural Safety, Vol. 23, pp. 331-344.

Stewart, M. G. (1996), Serviceability Reliability Analysis of Reinforced Concrete Structures, Journal of Structural Engineering, ASCE, Vol. 122, No. 7, pp. 794-803.

Warner, R. F., Rangan, B. V., Hall, A. S. and Faulkes K. A. (1998), Concrete Structures, Longman Press, Melbourne. 